\title{
The Expatriate Experience: A Case Study Of A Pharmaceutical Company In The European Union
}

Michele Geigle M.B.A., PhD, Schiller International University, USA

Naveen K. Malhotra, PhD, Eckerd College, USA

\begin{abstract}
This study examines the Cross-Cultural adjustment of expatriates entering into Belgium corporate and social society. The research was petitioned by the Organization of People Development of a multinational pharmaceutical corporation based within the European (EU). Concern existed regarding retention rates of expatriates and the formidable costs of failed expatriate assignments. Thirty upper level managers expressed an interest in participating in a series of interviews focused on their personal and professional experiences as expatriates. The methodological approach was qualitative in nature. The technique used was informal, in-depth interviews in tandem with a quantitatively based survey instrument to collect demographic data and satisfaction rates. Results revealed significant dissatisfaction with a number of dependent variables correlated with successful integration, i.e. personal and professional satisfaction and spousal or partner satisfaction. Narrative descriptions of acculturation adjustment provide depth into the challenges of expatriate's assignments. Researcher relied on Hofstede's (2001) cultural model for a greater understanding of "Culture's Consequences."
\end{abstract}

\section{INTRODUCTION}

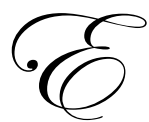

xponential growth of the Multinational Corporations (MNCs) engenders an urgent need for highly skilled, highly educated employees. No one country can contain the diversity of skills and expertise required to fill these needs. Scientists, researchers, physicians, financial analysts, managers, and a multitude of other professionals must be attracted and retained if MNCs intend to compete in a global environment. Cross-cultural adjustment has been identified as a key element in success rates of overseas assignments. Crosscultural adjustment has been defined as "the degree of psychological comfort with various aspects of a host country" (Black \& Gregersen, 1997).

This study was undertaken on the behest of the Organization of People Development of an EU based multinational pharmaceutical company. The corporation was experiencing a $2 \%$ turnover rate in the managerial expatriate staff while the industry average was $13 \%$. The number of employees had doubled in a four-year period. Thus, management was proactive in assessing the satisfaction rate of current employees. Research shows that cultural integration, adaptation, and adjustment are directly related to expatriate employee turnover (Schaffer \& Harrison, 1998).

\section{LITERATURE}

Studies conducted by Schaffer and Harrison (1998) connect expatriate integration and adjustment to employee satisfaction and turnover. Their work concluded that "...work related factors of job satisfaction and organizational commitment were significant predictors of expatriate withdrawal cognition."

Academic research reveals that multinationals often do not take into account the intercultural competencies necessary for successful adaptation in expatriate assignments. However, failure to succeed in these assignments is 
not based on professional skills, but rather the inability to adjust and integrate into the host culture. And the failure of the corporation to retain these individuals once hired can be financially disastrous.

At the humorous level cultural differences provide very funny stories. However, when shock becomes clash, levels of efficiency drop considerably and companies and individuals suffer (Raynaud \& Jardine, 2001). Expatriates are costly to train and retrain. Poor cross-cultural adjustment decreases job performance and satisfaction (Vianen \& Brown, 2004). Cultural misunderstandings generate psychological stress (Gelade \& Ivery, 2003.

Black and Gregersen (1997) report that 10 to 20 percent of expatriates emanating from the United States return prematurely due to dissatisfaction with their overseas employment. In addition, the performance of one third of those that stayed in their post was less than satisfactory (Black \& Gregersen). Research from Brigham Young University indicates that international assignments can cost an average of \$2 million per employee. "In 100 assignments, 25 employees will go to work for the competition, which is the equivalent of letting $\$ 50$ million walk right out the door. This turnover rate is double that of managers who stay at home" (Mark, 1999). With rapid expansion of the global market, MNCs are finding it increasingly difficult to identify and develop key expatriate talent.

\section{THE HOST COUNTRY}

Understanding both the home and host cultures is imperative to successful cultural integration. This study focuses on Europeans, Americans, Canadians, and African employees integrating into Belgian corporate and social society. Belgium has a unique history that plays a significant role in its current culture. It is a country drenched in the history of war. Millions have died on Belgian soil.

The Belgians were a Celtic tribe long before the country itself was formed. They were conquered by Julius Caesar in $52 \mathrm{BC}$ and later dominated by German Franks. In the $7^{\text {th }}$ century, the Belgae were Christianized and Belgium became part of the Holy Roman Empire. In the $15^{\text {th }}$ century Belgium was inherited by Spain and Catholic rule was enforced. Religious fervor gripped the land. Thousands were imprisoned or executed. From the 1600 to 1830, the Protestant-Catholic wars along with France, Austria, Spain, Germany, and the Netherlands used Belgian land as a battleground.

Though Belgium maintained a policy of neutrality, Germans invaded in 1914 and again in 1940, overtaking the country in three weeks during the Second World War. The Battle of the Bulge occurred in Bastogne in the Ardennes, the rich forest region of the south.

Belgium's desire for peace, compromise, and neutrality has finally found substance in her current role, the home of diplomacy, the European Union. How does a country so ravaged by centuries of war respond and adapt in the $21^{\text {st }}$ century? This research reveals the history, traditions, customs, and attitudes of the Belgium people, reflected through the expatriate population attempting to integrate itself into the social and corporate society in Belgium.

\section{THE METHODOLOGY}

Face to face interviews were conducted for quick feedback with upper level cadre of employees from six different divisions of an EU based pharmaceutical company. Research indicates that most often a corporation transfers only its mid to upper level employees to foreign assignments. The approach was ethnographical in nature where subjects were informally interviewed for periods lasting 30 to 90 minutes each. These interviews took place in the various offices of the expatriate managers.

\section{THE PARTICIPANTS}

Thirty upper level managers participated in this study. Twelve nationalities were represented. Twenty one (21\%), the largest representation, were Germans, many of whom had never visited Belgium prior to accepting their current assignment. Figure 1 depicts the country breakdown. Eighteen males and twelve females participated. 
Respondents worked in a variety of Departments: clinical, legal, marketing, manufacturing, regulatory, and research and development.

The majority of participants $(60 \%)$ were between the ages of 26 and 45 . Sixty three percent were married and $43 \%$ had spent between one and three years in Belgium in their current assignment. All participants spoke English, 77\% French, 30\% German, and 3\% Flemish. Spanish, Italian, Persian were some of the other languages of fluency.

\section{Expatriate Nationalities}

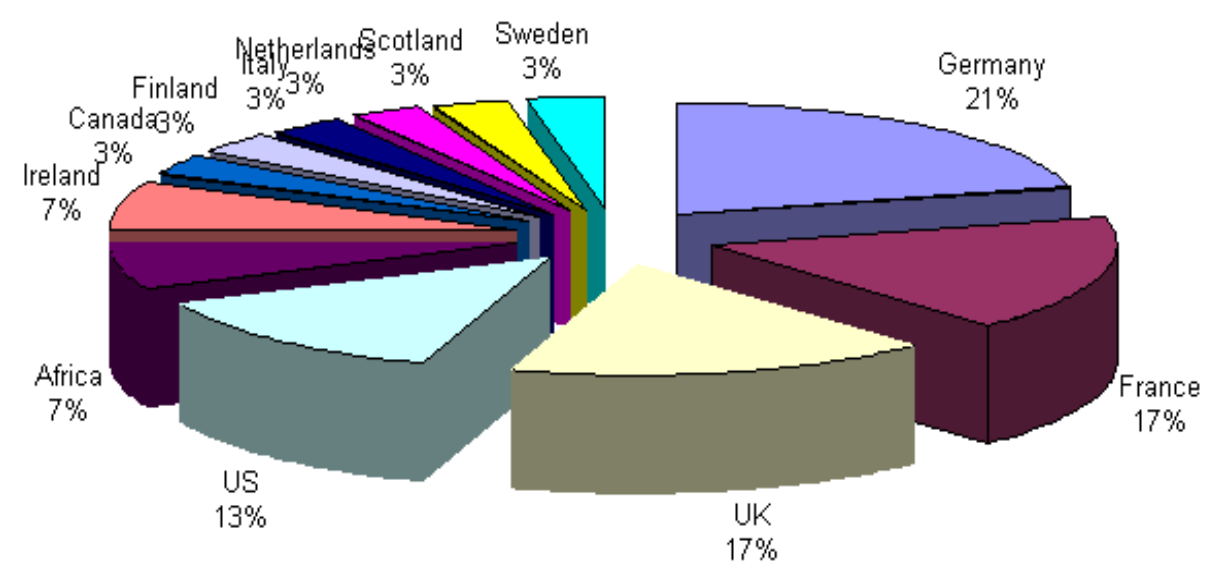

Figure 1

\section{THE QUESTIONNAIRE}

The research questionnaire was composed of four sections. Part I gathered demographic data including nationality, age, gender, education, language fluencies, occupation, and prior expatriate experience. Part II was categorized into seven initial sections with two new inquires added at the request of the Human Resource Department. They consisted of open-ended questions regarding the following: The expatriate description of the assignment, issues relating to personal integration, spousal integration, family integration, the corporate culture, the social culture, and challenges or specific problems. Attitude toward training and supervisors was also added.

The third part of the questionnaire consisted of a "Satisfaction Rating Scale" with the response design presented in a Lykert-type scale with $1=$ Satisfaction to a very great extent and $5=$ Not at all satisfied. In Part IV the following three questions were posed to the respondents: 
1. How can productivity and satisfaction be enhanced at your workplace?

2. In your opinion what capabilities contribute to the success of an overseas assignment?

3. How can employers assist with their employees with the repatriation process?

Participates were free to expand on or omit segments of section II and IV.

\section{RESULTS}

The level of satisfaction experienced by the group as a whole was quite positive. No one nationality indicated exceptional dissatisfaction in any particular area. Three areas of concern, however were 'Salary', 'Benefits', and 'Spouse or Partner'

Professional Satisfaction: $77 \%$ of respondents indicated they were 'to a very great' or 'to a great extent' satisfied with their work.

Personal Satisfaction: $73 \%$ of respondents indicated they were 'to a very great' or 'to a great extent' personally satisfied.

Challenged by the Work: $70 \%$ of respondents indicated they were 'to a very great' or 'to a great extent' challenged by the work.

Satisfaction with Salary: $30 \%$ of respondents indicated they were 'to a very great' or 'to a great extent' satisfied with the salary. Forty Seven percent (47\%) were satisfied 'to some extent, $13 \%$ were satisfied 'to a small extent', and $10 \%$ were not at all satisfied.

Satisfaction with Benefits: $42 \%$ of respondents indicated they were 'to a very great' or 'to a great extent' satisfied with the benefits. Thirty eight percent (38\%) were satisfied 'to some extent; $15 \%$ 'to a small extent' and $4 \%$ 'not at all satisfied'.

Spousal or Partner Satisfaction: 38\% of respondents indicated that their spouse or partner were 'to a very great' or 'to a great extent' satisfied with the expatriate assignment; $31 \%$ 'somewhat satisfied, $19 \%$ satisfied 'to a small extent, and $13 \%$ 'not at all satisfied.

These statistics make some powerful inferences regarding turnover forecasting. Many of the comments in Section IV relate directly to these findings:

\section{PARTICIPANT COMMENTS}

"The financial picture was not clear when the move was made. The cost and quality of live(life) are questions that remain."

"I fail to see the full implications of this move, financially and personally. Attempts to negotiate a financial settlement are only partially resolved after 4 years."

"I view this move as financially irresponsible to my family."

"I initially sat down with the HR department and asked direct questions like, "Define 'Credits' and 'Allowances,' and explain the expatriate tax package. I never got a direct answer. I thought the person was ignorant of the subject."

Additional comments reveal more in-depth cultural enigmas: 


\section{CULTURAL ISSUES}

Open discussion allowed the individuals to comment or expand on statements within the questionnaire. When given the time to expand on their comments, consistent patterns began to emerge. Cultural misunderstanding, misperceptions, and miscommunication comprised the majority of comments. Often, the speaker was unaware of the source of conflict. The following excerpts afford additional insights in terms of specific challenges faced by these expatriates and depict the mindset that reflects the difficulty experienced when adapting to a new culture.

\section{SOCIAL CULTURE}

"Initially there is a mindset that the new culture is inferior, less intelligent. There is little trust with government, police, and transportation. Communication is inefficient. Time moves one to a respect of another." (German)

"Belgium was occupied by many foreign armies, invaders. Belgians distrust authority. They 'hide' issues as one would hide in war like condition. This hinders integration." (British)

"Look at the farms in other countries. They are open, at times, no fences exist. Now look at a Belgium farm. It is a fortress. All life occurs within the walls, completely protected. Watch the architecture. It reflects a state of mind." (German)

"Belgians are family oriented people. If you are not in the family, you must knock hard on the door of society to be let in." (African)

"Belgium is a closed society. It is a Catholic society and they do not believe that an extrovert is good. They suppress one verbally. You become distant and quiet." (Netherlands)

"I am hungry for a social life here. You must book engagements weeks in advance. There is no spontaneity here. There are rules of social engagement that you must follow." (Irish)

\section{CORPORATE CULTURE}

"Rules are not consistent. One set exists for a certain situation but the others are treated differently in the same situation. I refuse to relate this to my nationality or my gender (female). You cannot swim in cultural differences. You will drown." (Ghanaian, Africa)

"In my country, logic and reason supports views. These are valuable tools. In Belgium, this does not matter. If your status is low, your reason is disregarded." (Sweden)

"I have a feeling that there is a fear of authority here in Belgium and at this company. For instance, if someone has a point to make they wait for a lead from this hierarchical structure. No one just thinks and processes freely." (German)

"There is a soft approach to communication here. Much more discussion, conversation, and collaborations (occur) before the task is undertaken." (German)

"There is a political system that is not acceptable here. You enter at ground zero. You must fit into a hierarchy. Prior successes are not looked at. It is friendly and collaborative on the surface." (American)

"In (this corporation) the structure is life an upside down 'V'; too many mangers at the top and too few workers. Rank is very important." (African) 


\section{SPOUSAL/PARTNER SATISFACTION}

"My wife is a hydrologist, accustomed to adapting. She worked in African and India on water distribution designs and methods. When we moved to Belgium, she was pregnant with our second child. She is not working now." (Canadian)

"We divorced. It would not work." (Finish-Female)

"My spouse is Belgium. We are fully integrated." (Swedish)

"My husband was unable to find work in Brussels. He lives in the United States now." (French)

"We are considering leaving. My wife has supported all my efforts but she too is dissatisfied with finances. Otherwise, she is happy with the move though she was unable to find work that pays. She throws herself into volunteering at the school." (American)

"My wife was a home health care professional in the UK. She worked with the primary health care team. Duties include visiting and assessing families. There is a greater need for intimacy, culturally speaking. Due to the language barrier, she was unable to find similar employment." (British)

\section{DISCUSSION}

Traditionally, preparation for a cross-cultural assignment has focused on a brief study of the history, language, climate, and customs of the host culture. Though important, these briefings have been far too narrow in breath and depth to equip the expatriate with the training and skills necessary to understand the core cultural values that lie at the root of the challenges described.

The statements from expatriate employees, along with the dissatisfaction rates, suggest typical cultural integration problems along with elements of culture shock syndrome. Some individuals were aware of the personal processes or steps to integration while others were quite unfamiliar with the cognitive, affective, and behavioral situations experienced in the host culture. According to Derr (1988), the barriers to cultural integration are due to ignorance of the culture and not rejection of it.

Clarity of cultural differences can be found in Hofstede (2001) model, an analytical tool that can be used to quantitatively view cross-cultural differences by examining the constructs of Uncertainty Avoidance and Power Distance.

Uncertainty Avoidance refers to how comfortable people feel toward uncertainty or ambiguity (Hofstede, 2001). Cultures with a low score feel more comfortable with ambiguity. Belgium ranks high on this scale, 94. It is categorized by "tighter" societies, more formal rules, an elaborate legal system, and an avoidance of conflict or competition. The following chart depicts the nationalities of the expatriates and their rank toward Uncertainty Avoidance.

\begin{tabular}{|ll|ll|ll|}
\hline Belgium & 94 & Finland & 59 & USA & 46 \\
\hline France & 86 & Netherlands & 53 & Ireland & 35 \\
\hline Italy & 81 & Africa & 52 & Great Britain & 35 \\
\hline Germany & 65 & Canada & 48 & Sweden & 29 \\
\hline
\end{tabular}

Offerman (1995) presents evidence from MNCs suggesting that leaders from High Uncertainty Avoidance societies are viewed by their subordinates as controlling more and delegating less. Such leaders were also rated less approachable by staff thus hindering communication with in the organization.. 
Power Distance refers to the extent to which less powerful members of a society accept the unequal distribution of power. In other words, they are more accepting of a hierarchy, rank, or a caste system of power. As the following statistics reveal, Belgians accept the difference of unequal power distribution much more readily than most other nationalities in this study.

\begin{tabular}{|ll|ll|ll|}
\hline Belgium & 65 & USA & 40 & Canada & 39 \\
\hline France & 68 & Netherlands 38 & Finland & 33 \\
\hline Africa & 64 & Germany 35 & Sweden & 31 \\
\hline Italy & 50 & Great Britain 35 & Ireland & 28 \\
\hline
\end{tabular}

\section{IMPLICATIONS FOR PRACTICE}

Although the subject of this study was a pharmaceutical MNC based in the European Union, the issues of cross-cultural integration are equally applicable to all MNCs. Empowered by this type of cultural knowledge, expatriates and MNCs can adjust more quickly and with far less adversity. Before selecting employees for overseas transfer, Human Resource professionals must evaluate them on, not only technical suitability, but also various psychological issues of emotional maturity, flexible thinking, to adjust, previous expatriate experience, language, openness to different cultures, desire to learn new customs and traditions, and family support. In addition, extensive in-depth country specific business and cross-cultural training, both, before departure and after arrival must be provided to ensure success. Raynaud \& Jardine (2001) contend that expatriates and MNCs seriously consider the impact of a move on spouses. Research indicates that one of the most important factors in failed expatriations is unhappiness of the spouses whose adjustment difficulties are by far greater than those of the working partners. Predeparture activities and attitudes had a significant effect on the post-arrival adjustment of the spouses (Simeon \& Fujiu, 2000). MNCs need to realize that for the expatriate's job satisfaction and organizational socialization in the host country are important predictors of effective cross-cultural adjustment ( Hung-wen \& Ching-Hsiang, 2006).

\section{REFERENCES}

1. Black, J., \& Gregersen, H. (1997). When Yankees Come Home: Factors Related to Expatriate and Spouse Repatriating Adjustment. International Business Studies. 22 (3), 671-694.

2. Chew, J. (2004). Managing MNC Expatriates Through Crisis: A Challenge For International Human Resource Management. Human Resource Management. 12 (2), 1-30.

3. Derr, C. (1988). Managing New Careerist. Administrative Science Quarterly. 33 (1), 148-149.

4. Gelade, G., \& Ivery, M. (2003). The Impact of Human Resource Management and Work Climate on Organizational Performance. Personnel Psychology. 53, 383-404.

5. Hofstede, G. (2001). Culture's Consequences: Comparing Values, Behaviors, Institutions and Organizations Across Nations. Thousand Oaks, CA.: Sage Publications.

6. Hung-Wen, L., \& Ching-Hsiang, L. (2006). Determinants of the Adjustment of Expatriate Managers to Foreign Countries: An Empirical Study. International Journal of Management.

7. Mark, M. (1999). Companies Losing Millions to Competitors in the Form of Trained Expatriates. Brigham Young University. Spring,

8. Offerman, L. (1996). Leading and Empowering Diverse Followers. Kellogg Leadership Studies Project, George Washington University. March,

9. Raynaud, M \& Jardine, E. (2001). Critical Expatriate Skills: Preventing Culture Clash. Corporate Relocation News, August issue.

10. Schaffer, M., \& Harrison, D. (1998). Expatriates' Psychological Withdrawal From International Assignments: Work, Non-Work, and Family Influences. Personnel Psychology. 51 (1), 87-118.

11. Simeon, R., \& Fujiu, K. (2000). Cross-Cultural Adjustment Strategies of Japanese Spouses in Silicon Valley. Employee Relations. (6), 594-611.

12. Vianen, A., \& Kristoff-Brown, A. (2004). Fitting in: Surface and Deep-Level Cultural Differences and Expatriates' Adjustment. Academy of Management Journal. 47 (5), 697-709. 
NOTES 